\title{
FACTORS INFLUENCING THE USE OF GREEN LOGISTICS: THEORETICAL IMPLICATIONS
}

\author{
Vidas Tamulis ${ }^{1}$, Andrius Guzavičius ${ }^{2}$, Lina Žalgiryte ${ }^{3}$ \\ ${ }^{1}$ Kaunas University of Technology, Lithuania, andrius.guzavičius@ktu.lt \\ ${ }^{2}$ Kaunas University of Technology, Lithuania,vidas.tamulis@gmail.com \\ ${ }^{3}$ Kaunas University of Technology,Lithuania, lina.zalgiryte@ktu.lt \\ cross'ref http://dx.doi.org/10.5755/j01.em.17.2.2202
}

\begin{abstract}
As the climate change is getting more and more visible through global warming and more rapidly appearing weather anomalies. Planet resources are used more widely and rapidly due to that coming to an end. World society is concerned, how to affect global warming effect, how to find measures to preserve natural resources and promote recycling. In this global process logistics plays very important role, as it is one of the main pollution sources and resource user. Thus the rising attention to the greener solutions, doesn't leave logistics aside. Many countries make steps to promote greener technologies and recycling in logistics field, as the logistics process cannot be stopped or make completely green, as the, necessary resource is fuel. Full stop of logistics it would lead to economics stop. Nevertheless not only technology drives logistics, also logistic processes influence heavily on ecology. If processes are not efficient, they also lead to wasting of resources. So the aim of this article is to reveal factors influencing green logistics use at the level of company from the theoretical point of view. First off all the difference between the conceptions of green logistics and logistics are presented. Secondly the use of green logistics and it's impact to global ecology are discussed. Finally the solution of using green logistics and the factors of using it through the theoretical implications are presented.

Keywords: social corporate responsibility, green logistics system, sustainable development, ecological systems, fuel consumption efficiency.

JEL Classification: D62, F13, Q01, Q50.
\end{abstract}

\section{Introduction}

Logistics is heavily dependent from the world economy, as the economy is growing; logistics is also growing, as the demand for the movement of goods is growing. During the crisis economy is slowing down and the demand for the logistics service goes down also. But the world economics without logistics would stop completely, Manufacturers couldn't get raw materials, customers - products - food, petrol, electricity. At the level of company logistics process is getting more and more important in almost every company's daily life.

In this article the factors influencing greener logistics are analyzed. Starting from the overview of the growth of the logistics and its influence on the world economy, we will analyze its impact on the global warming process and what technologies are being created to greener it. In the second chapter we will analyze factors, which are influencing logistics process and may lead to increased its effectiveness and getting greener logistics. In the last chapter we will analyze which factors are financially efficient and at the same time giving greening effect and which factors give only greening effect or slowing logistics process. This article is based only on theoretical findings in the literature and no empirical research will be made.

Aim of the study - to built theoretical framework of factors influencing green logistics use at the level of company

Tasks of the study:

- to define differences between the concepts of logistics and green logistics;

- to evaluate the use of green logistics and it's impact on global ecology;

- to present the solutions of using green logistics and factors influencing it.

Research methods - the comparative and structural as well as the qualitative and quantitative analysis of scientific economic literature, graphical modelling and logical analysis.

\section{Differences between logistics and green logistics}

Different authors define logistics in the similar way. For example Harrison and Van Hoek (2008) defines logistics as "the task of coordinating material flow and information flow across the supply chain"(p.4). [5] Christopher (2007) states that logistics is the process of strategically managing the procurement, movement and storage of materials, parts and finished inventory (and the related information flows) through the organization and its marketing channels in such a way that current and future profitability are maximized through the cost-effective fulfilment of orders. Mangan and ect. (2008) summarise that 
logistics involves getting, in the right way, the right product, in the right quantity and right quality, in the right place at the right time, for the right customer at the right cost. In the supply chain management glossary (2010) logistics is defined as "the process of planning, implementing, and controlling procedures for the efficient and effective transportation and storage of goods including services, and related information from the point of origin to the point of consumption for the purpose of conforming to customer requirements. This definition includes inbound, outbound, internal, and external movements" (p. 114). It can be seen that different authors stresses that logistics includes the transfer of goods and information, which must be planed, implemented and controlled in the most efficient way in order to meet the needs of the customer.

The term "green logistics" is defined as supply chain management practices and strategies that reduce the environmental and energy footprint of freight distribution, which focuses on material handling, waste management, packaging and transport (Rodrigue and etc, 2012). Thiell and etc. (2012) notice that green logistics consists of all activities related to the eco-efficient management of the forward and reverse flows of products and information between the point of origin and the point of consumption whose purpose is to meet or exceed customer demand. Lee and Klassen (2008) describe green logistics as Green Supply Chain Management that can be defined as a organizations activity taking into account environmental issues and integrating it into supply chain management in order to change the environmental performance of suppliers and customers.

\section{The use of the green logistics and its impact to global ecology}

Growing focus on world ecology process puts big stress on logistics process, as it is one of the biggest reasons for the world global warming and polluters. Transport among the world permanently is emitting huge amounts of carbon dioxide, nevertheless new green technologies are invented and promoted. In the European strategy (2010) there is a big attention on the sustainable development taken. On of the purposes of the European strategy till 2020 is:" to reduce greenhouse gas emissions by at least $20 \%$ compared to 1990 levels or by $30 \%$, if the conditions are right; increase the share of renewable energy sources in our final energy consumption to $20 \%$; and a $20 \%$ increase in energy efficiency". In order to achieve this green logistics plays an important role.

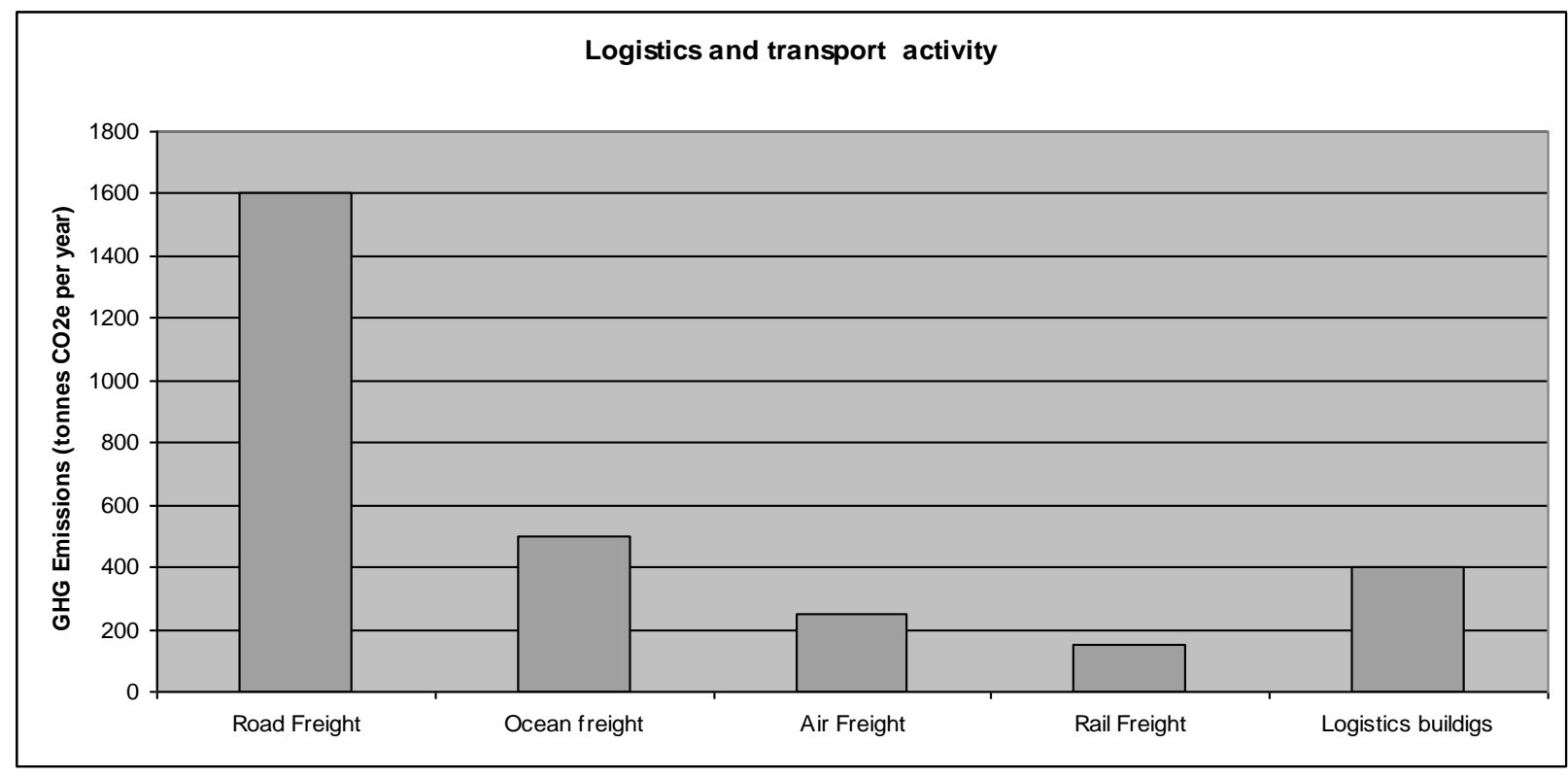

Figure 1. Logistic activity and GHG emission

According to the World economic forum data (2009) road transport is the biggest polluter among all transport types (figure 1). Road transport is one of the most popular transport modes due to its flexibility, mostly developed road system, rather low affect due to weather conditions. Other transport modes have more limitations due to flexibility, distribution network or dependence on the weather conditions. The main attention is put to road transport as there are big spaces to reduce its emissions by changing road transport to other modes, which are more environment friendly. Having the biggest part of emissions road transport is not the most inefficient transport mode. According to the World economic forum data (2009) the most inefficient 
transport mode is airfreight. Rail and sea freight are the most efficient transport modes. The big stress is put on changing to efficient transport modes. Nevertheless this may cause to companies more problems, as benefit. Problems of despeeding of supply chain may arise, inflexibility, increased inventory, more control units concerned with delivery information and etc. (figure 2).

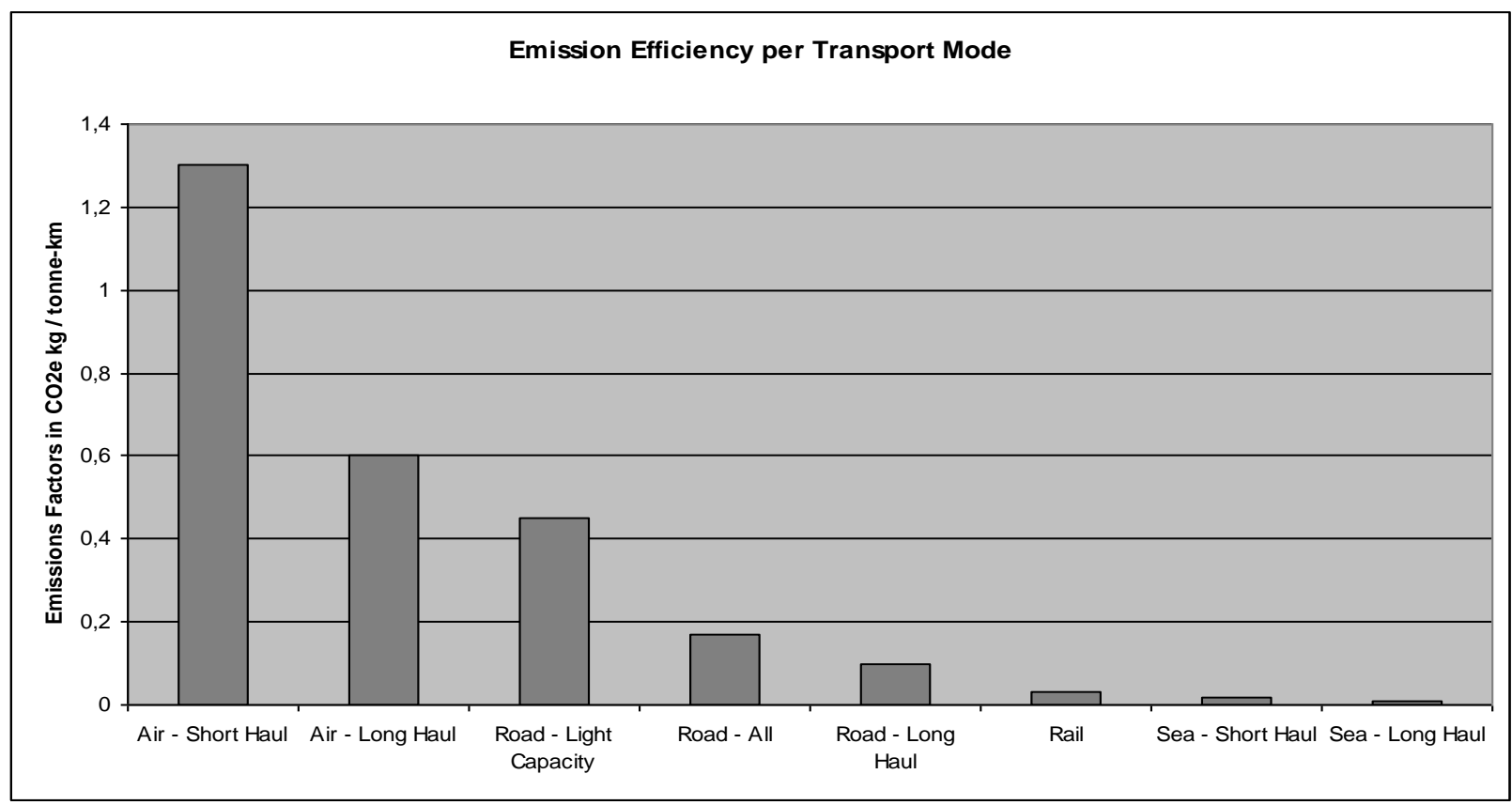

Figure 2. Approach of effectiveness in logistical system

\section{The solutions of using green logistics and the factors influencing it}

Although in country and European level is declared the importance of ecology, but the statistics shows that environmentally the most friendly transport modes - rail and water, are not so frequently used, as they haven't such flexibility and service level like road transport. Analyzing literature were found five solutions affecting emissions in transport sector.

1. Clean vehicles. (Thiell and etc. 2011)

2. Multimodal shipment (McKinnon and etc. 2010)

3. Freight consolidation (Thiell and etc. 2011)

4. Road, traffic, infrastructure(McKinnon and etc. 2010)

5. Home delivery (World Economic Forum 2009)

\section{Clean vehicles}

The main engines in all transport modes -internal combustion (road transport, sea, rail) and jet and screw engines (air transport). All transport modes need fuel, which is made from oil and during burning process emit $\mathrm{CO} 2$ gas. Engineers are modernizing these engines to make them as much clean as possible with lowest fuel consumption. Having in mind that oil resources are running out, for future we will need alternative sources to move transport means. Currently there is no technology on the market, which could substitute internal combustion or jet engines effectively. Thus we can analyze current modern technologies, which are present on the market and if their greenness gives any use to the company owing such transport vehicles. For the future is forecasted for long haul truck fuel efficiency improvements of $20-30 \%, 35-45 \%$ reduction in aircraft emissions du to engine and fuselage redesigning, and for containerships new technologies allowing to emit till 70\% CO2 (McKinnon 2011).

Road taxation in some countries depends on truck ecology class. What is one of reasons to use environmentally friendly transport vehicles. Countries like Germany, apply lower rates for using its roads. In Lithuania ecological transport is not promoted the same rate applies to all trucks.

\section{Multimodal shipments}

Intermodal Transportation: Transporting freight by using two or more transportation modes such as by truck and rail or truck and oceangoing vessel. (Council of Supply Chain Management Professionals 2010). 
Looking stricter to $\mathrm{CO} 2$ emissions, more attention is paid to multimodal shipment, changing to more environmentally friendly transport means - rail and sea (Naim, 2010). Comparing sea and air deliveries, sea deliveries make $1-2 \%$ of air emissions per tone-km. The effect in $\mathrm{CO} 2$ emissions is very significant. But what changes, positive or negative can bring modal change. Do green solution will bring desired effect to the company.

Road transport is commonly used for possibility to deliver goods door-to-door due to developed road system and its flexibility. Air conditions may heavily effect delivery of goods (McKinnon, Cullinane, Browne, Whiteing 2010).Air transport is very fast transport delivering goods at big distances, but has limited delivery network and very expensive. Very depending on air condition, even volcano eruption may cause stop of air transport. Delivery of goods and distribution from terminal is made by other means of transport (McKinnon, Cullinane, Browne, Whiteing 2010).

Rail transport has almost no effect on weather conditions, possible to deliver big amounts of goods in one transport unit at cheap price, at close distances road transport is more competitive, delivery is possible where railroads are built, not every company has rail road close to it (McKinnon, Cullinane, Browne, Whiteing 2010). Sea transport is one of the cheapest transport modes, doesn't need road system, but at the same time s one of the slowest transport modes, is heavily dependant on weather conditions, limited network like in air transport.Ships and railways are the most environmentally friendly transport means, but their have the poorest service. Air and road transport have much higher quality ratings and are selected more by the customers.

According studies intermodal solutions help to save money, but are slower, not so reliable comparing with uni-modal road transport . Cargo tracking in multimodal means is more difficult. Almost impossible to track which transport mode damaged goods, as the container may undergo all way from supplier to client sealed and no visible damage may be seen during all way. Every transport mode operator may be claiming that the goods were taken without possibility to check what's its condition, if the goods were not damaged (McKinnon, Cullinane, Browne, Whiteing 2010). Damage of the goods may occur in any transport mode.

\section{Freight consolidation}

Freight consolidation helps to use transport more efficiently, delivering more goods with one transport means. Deliveries with half empty trucks are economically not useful. Freight company earns more money, delivering more goods with one transport means, what reduces freight cost per $\mathrm{kg}$. At the same time emissions are reduced as the goods are delivered with fewer transport means. In some cases direct delivery may be very expensive. For increasing freight consolidation are logistics centres. [20] Effective logistics centre network allows distributing effectively goods along the whole world by all transport modes [21].

\section{Road, traffic, infrastructure}

Traffic flows, allocation of distribution centres, road infrastructure plays considerable role in emission reducing. Heavy transport's, struggling in the city, extremely in rush hours, fuel consumption may increase $130 \%$ or even more (Wu, Dunn, 1995). Driving with heavy transport into the may be because of missing detour around the cities, distribution centre or client location inside the city. Moving distribution centres outside the city allows heavy traffic to leave outside the city and to consolidate the goods that have to be delivered to the city. Modern road system helps to avoid traffic jams, run fewer kilometres to deliver all goods.

\section{Home delivery}

Among larger economies for shopping with cares are is driven about 126 billion kilometres. Changing it to home delivery would help to reduce traffic congestion, reduce emissions. Growing segment of ecommerce, in some countries around $20 \%$ per year, has the potential to reduce trip number significantly.

\section{Factors affecting green logistics}

Green solutions not always mean benefit for the company, some of these solutions may cause disadvantages to the companies and there will be no interest in green solutions, but will be chosen bigger revenue, achieved without paying attention to the footprint on the environment left during distribution process.

Schmied (2010) distinguishes four factors affecting green logistics - company, customers, politics, and society. According picture 3, we may see, that each of them may affect green solutions.

Customers may require products delivered with clean vehicles or in such manner that the emissions are minimized, forcing suppliers to go to green solutions, although normally they wouldn't do it. Customers can go to superstores that are built in places having convenient road system and avoid that are built in such 
way, that reaching them may cause extra emissions. Perhaps the biggest affect from customers may be home delivery, as they are the direct users of this service.

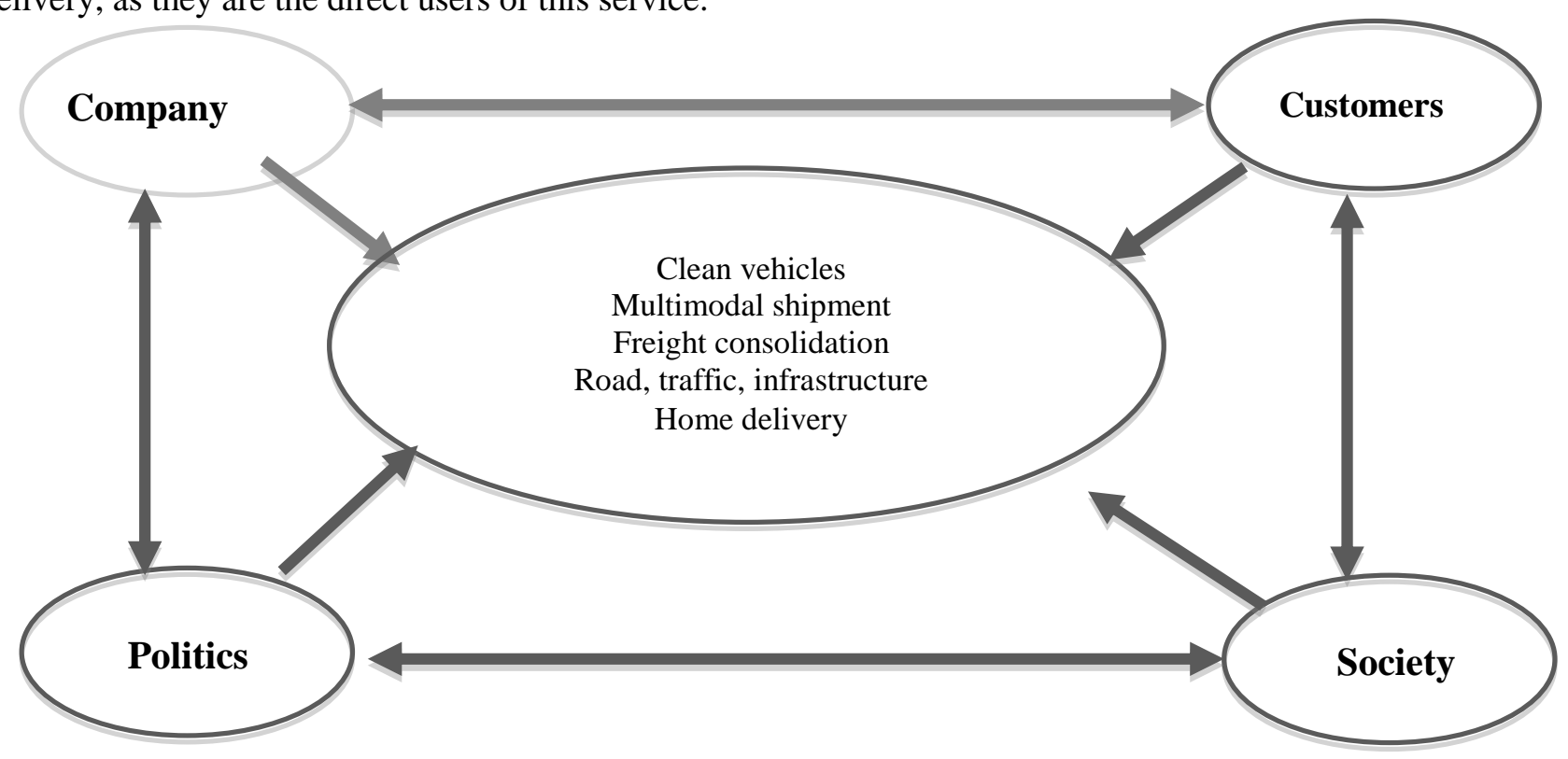

Figure 3. Factors affecting green logistics

Society has also the power to affect all these solutions. Like the customers requiring and promoting of purchases of green delivered product, causing companies to move green. Promote home delivery, saving many kilometres driven to supermarkets.

Politics is the strongest factor. Having force to publish laws, give incentives, regulate infrastructure, politics are in close touch with every solution. From their actions will depend if the companies will be interested to use green logistics or stay with old technologies and solutions.

Politics, society, companies, customers are closely related with each other. Politics are elected by customers and society, companies must obey laws from politics and need of customers. To create more exact view of interrelation must be made separate analysis.

In the debate on the environmental impact of logistics and transportation, several measures have been suggested by researchers and policy-makers to come to terms with the current trend of growing $\mathrm{CO} 2$ emissions (IPCC, 2007). Although all operations within a logistics system are important when considering a reduction, transport operations account for a large share of any logistics system's emissions (Wu and Dunn, 1995) and, consequently, much of the recent logistics literature has focused on the sustainability of transport operations within the system (see for example Edwards et al., 2010; Sanchez-Rodrigues et al., 2010; Wolf and Seuring, 2010; Lieb and Lieb, 2010). In a European context, a measure commonly suggested to reduce the environmental impact of transportation is the shift in transport modes, from faster, more polluting modes such as road and air transport to slower and less polluting modes such as rail or maritime transport (McKinnon, 2008; European Commission, 2001). In particular, intermodal road-rail solutions, where a combination of road and rail transport is utilized, has been suggested as a promising way to reduce the $\mathrm{CO} 2$ emissions from the transport operations within a logistics system (Flodén, 2007; Swedish Government, 2006; European Commission, 2001).

\section{Conclusions}

1. Logistics focuses on transfer of goods, information and coordination of this process. Green logistics focuses how to reduce environmental impact of logistics processes, how to switch to greener transport modes. Logistics process focuses on optimization, reducing costs, increasing delivery speed, and gaining maximal revenue. Not always it focuses if the achieved result was using environmentally friendly solutions or transport modes. Green logistics focuses on all logistics fields where appear emissions, waste, inefficient use of resources. Some of green solutions may be not useful for business, as it may reduce flexibility of logistics process.

2. It is important to present proposals to modernize and decarbonise the transport sector thereby contributing to increased competitiveness. This can be done through a mix of measures e.g. 
infrastructure measures such as early deployment of grid infrastructures of electrical mobility, intelligent traffic management, better logistics, pursuing the reduction of $\mathrm{CO} 2$ emissions for road vehicles, for the aviation and maritime sectors including the launch of a major European "green" car initiative which will help to promote new technologies including electric and hybrid cars through a mix of research, setting of common standards and developing the necessary infrastructure support.

3. Companies are directly related with using clean vehicles, multimodal shipment, and freight consolidation. Solutions helping to save costs and to increase revenue are of main priority for them. But some of solutions may be not so profitable or causing more work to achieve green effect. If truck with newest technologies causing less emissions cost more than not so advanced truck and its operation costs more, then company wouldn't have interest to use such truck, which causes more expenses as gives profit, just because it is green. We could state that company is the least interested factor in picture 3 to use green solutions, if it doesn't give any use. Companies are interested in reaching more revenue regardless how it is achieved.

\section{References}

1. Alan C. McKinnon, Sharon Cullinane, Michael Browne, Anthony Whiteing (2010). Green Logistics: Improving the Environmental Sustainability of Logistics

2. Alan Harrison, Remko Van Hoek (2008). Logistics Management and Strategy: Competing through the Supply Chain (3th Edition), p4 Prentice hall: Financial times, logistics and the supply chain, p. 3-33.

3. Christopher, M. (2007). Logistika ir tiekimo grandinès valdymas .p. 12

4. Dr. Jean-Paul Rodrigue, Dr. Brian Slack and Dr. Claude Comtois (2001). Green Logistics.

5. Dülfer (2005). Episoden des Logistik-Managements in Antike und Mittelalter.

6. Evers, P., Harper, D., Needham, P. (1996) The determinants of shipper perceptions of modes, Transportation journal, 36, 13-25.

7. Haw-Jan Wu, Steven C. Dunn. (1995). Environmentally responsible logistics systems.

8. http://cscmp.org/ Council of Supply Chain Management Professionals, 2010

9. http://people.hofstra.edu/geotrans/eng/ch3en/conc3en/ch3c1en.html Dr. Brian Slack, Dr. Jean-Paul Rodrigue and Dr. Claude Comtois, 2012.

10. http://people.hofstra.edu/geotrans/eng/ch8en/appl8en/ch8a4en.html Dr. Jean-Paul Rodrigue, Dr. Brian Slack and Dr. Claude Comtois, 2012.

11. http://www.greenlogistics.org/themesandoutputs/wm1/framework.htm, 2012.

12. http://www.kfz-steuer.de/, 2012.

13. http://www.projectsmonitor.com/detailnews.asp?newsid=6968, B.P. Nansi, 2012

14. http://www.volvotrucks.com/trucks/lithuanian-market/lt-lt/trucks/environment/pages/fuel_consumption.aspx, 2012.

15. John Mangan, Chandra Lalwani, Tim Butcher (2008). Global logistics and supply chain management, p. 9

16. Julius Algimantas Urbonas (2005). Tarptautinè logistika.

17. Lee, Su-Yol, Klassen, Robert D. (2008): Drivers and Enablers That Foster Environmen- tal Management Capabilities in Small- and Medium-Sized Suppliers in Supply Chains, in: Production and Operations Management Society, Jg. 17, H. 6, S. 573-586.

18. LOGISTICS \& SUPPLY CHAIN INDUSTRY AGENDA COUNCIL FINAL REPORT 2010-2011, World economic forum.

19. Ludvigsen, J. (1999) Freight transport supply and demand conditions in the Nordic Countries: recent evidence. Transportation journal, 39, 31-54.

20. Marcus Thiell, Juan Pablo Soto Zuluaga, Juan Pablo Madiedo Montanez, Bart van Hoof, (2011). Green Logistics Global Practices and their Implementation in Emerging Markets.

21. Ronald H. Ballou, (1997). business logistic: importance and some research oportunities.

22. Schmied, M. (2010): Green Logistics: Aktuelle Entwicklungen zur Standardisierung der CO2-Berechnung, Pra $\square$ sentation, Hannover 2010.

23. Vasco Sanchez-Rodrigues, Andrew Potter and Mohamed M. Naim, (2010). The impact of logistics uncertainty on sustainable transport operations.

24. W. Lemoine and Lars Dagnæs (2003). Globalisation strategies and business organization of a network of logistics service providers. 